\title{
Communication Sciences and Disorders Graduate Students' Strengths and Vulnerabilities Related to Resilience: A Survey of Graduate Programs
}

\author{
Janet Tilstra \\ St Cloud State University, jstilstra@stcloudstate.edu \\ Megan Coffman \\ megancoffman1@gmail.com \\ Teresa Gonia \\ tjgonia@gmail.com \\ Caroline Koziol \\ c3koziol@gmail.com \\ Ellen Liebe \\ ellenliebe@gmail.com
}

Follow this and additional works at: https://nsuworks.nova.edu/ijahsp

Part of the Higher Education Commons, and the Speech Pathology and Audiology Commons

\section{Recommended Citation}

Tilstra J, Coffman M, Gonia T, Koziol C, Liebe E. Communication Sciences and Disorders Graduate Students' Strengths and Vulnerabilities Related to Resilience: A Survey of Graduate Programs. The Internet Journal of Allied Health Sciences and Practice. 2019 Jan 01;17(3), Article 5.

This Manuscript is brought to you for free and open access by the College of Health Care Sciences at NSUWorks. It has been accepted for inclusion in Internet Journal of Allied Health Sciences and Practice by an authorized editor of NSUWorks. For more information, please contact nsuworks@nova.edu. 


\title{
Communication Sciences and Disorders Graduate Students' Strengths and Vulnerabilities Related to Resilience: A Survey of Graduate Programs
}

\begin{abstract}
Burnout in health care professionals may pose a threat to the quality of care provided in any setting. The purpose of this project was to examine dimensions related to future resilience in CSD graduate students. METHODS: In this project, 146 master's degree students from Communication Sciences and Disorders (CSD) programs in the Midwest completed an online survey regarding lifestyle stresses affecting resilience, and patterns in five areas correlated with resilience. RESULTS: Top lifestyle stresses affecting academics were general stress, maintaining mental health, and sleep difficulties. Notably, more than half of the participants reported feeling rested three or fewer days per week. Further, CSD students reported significantly higher incidence of general stress, mental health conditions, chronic health conditions, concern for a friend or family member's struggles, and sleep difficulty than college age peers. Positive factors identified related to resilience in CSD students included presence of professional networks and mentoring, maintaining positivity, opportunities for reflecting on strengths and weaknesses, and having a sense meaning in life. Respondent areas of resilience vulnerability were reduced optimism on a daily basis, limited sense of life balance, and hesitancy to discuss life issues or accommodation needs with faculty. Implications are discussed regarding CSD graduate programs' roles in fostering resilience. CONCLUSION: Professional programs can support and promote the development of personal and professional resilience in students training for healthcare professions. This survey project provides a starting point to describe patterns in CSD master's programs within the Midwestern region of the US.
\end{abstract}

\section{Author Bio(s)}

Janet Tilstra, PhD, CCC-SLP, is an Assistant Professor in the Department of Communication Sciences and Disorders at St Cloud State University. She is an American Speech-Language-Hearing Association certified speech-language pathologist and licensed speech-language pathologist in the State of Minnesota.

Megan Coffman, MS, is a graduate of St Cloud State University Master of Science program in speechlanguage pathology. She is a licensed speech-language pathologist in the State of Minnesota.

Teresa Gonia, MS, is a graduate of St Cloud State University Master of Science program in speech-language pathology. She is a licensed educational speech-language pathologist in the State of Minnesota.

Caroline Koziol, MS, is a graduate of St Cloud State University Master of Science program in speechlanguage pathology. She is a licensed speech-language pathologist in the State of Minnesota.

Ellen Liebe Radtke, MS, is a graduate of St Cloud State University Master of Science program in speechlanguage pathology. She is a licensed speech-language pathologist in the State of Minnesota.

\section{Acknowledgements}

Special thanks to LeighAnne Mahoney and Hannah Tilstra for their positive energy and timely assistance with manuscript preparation. 


\title{
1IVAHSP
}

\section{The Internet Joutnal of Allied Health Sciences and Practice \\ Dedicated to allied health professional practice and education}

Vol. 17 No. 3 ISSN 1540-580X

\section{Communication Sciences and Disorders Graduate Students' Strengths and Vulnerabilities Related to Resilience: A Survey of Graduate Programs}

\author{
Janet Tilstra, PhD, CCC-SLP \\ Megan Coffman, MS \\ Teresa Gonia, MS \\ Caroline Koziol, MS \\ Ellen Liebe Radtke, MS \\ St. Cloud State University \\ United States
}

\begin{abstract}
BACKGROUND: Burnout in health care professionals may pose a threat to the quality of care provided in any setting. The purpose of this project was to examine dimensions related to future resilience in CSD graduate students. METHODS: In this project, 146 master's degree students from Communication Sciences and Disorders (CSD) programs in the Midwest completed an online survey regarding lifestyle stresses affecting resilience, and patterns in five areas correlated with resilience. RESULTS: Top lifestyle stresses affecting academics were general stress, maintaining mental health, and sleep difficulties. Notably, more than half of the participants reported feeling rested three or fewer days per week. Further, CSD students reported significantly higher incidence of general stress, mental health conditions, chronic health conditions, concern for a friend or family member's struggles, and sleep difficulty than college age peers. Positive factors identified related to resilience in CSD students included presence of professional networks and mentoring, maintaining positivity, opportunities for reflecting on strengths and weaknesses, and having a sense meaning in life. Respondent areas of resilience vulnerability were reduced optimism on a daily basis, limited sense of life balance, and hesitancy to discuss life issues or accommodation needs with faculty. Implications are discussed regarding CSD graduate programs' roles in fostering resilience. CONCLUSION: Professional programs can support and promote the development of personal and professional resilience in students training for healthcare professions. This survey project provides a starting point to describe patterns in CSD master's programs within the Midwestern region of the US.
\end{abstract}

Keywords: wellness, resilience, burnout, healthcare professions, graduate school, speech-language pathology 


\section{INTRODUCTION}

Risk for burnout is high for professionals working in healthcare professions. ${ }^{1-3}$ Burnout is defined as physical and emotional exhaustion resulting from workplace adversity or stress. ${ }^{1-3}$ Research suggests healthcare professionals who experienced burnout were more likely to leave their profession, had decreased life satisfaction, and provided lower quality of patient care. ${ }^{4}$ In contrast to burnout, professionals who "maintain[ed] personal and professional wellbeing in the face of on-going work stress and adversity"5 are considered resilient. Despite experiencing similar levels of workplace stress, resilience professionals, in contrast to those who experienced burnout, successfully rebounded from professional adversity. See McCann, Bedoe, McCormick, Hubbard, Kedge, Adamson, \& Huggard (2013) for a comprehensive review of resilience patterns in health professions. ${ }^{5}$

Recognizing the personal and professional implications of resilience, coordinators of healthcare training programs have become intentional about fostering resilience in future and early career professionals rather than waiting to treat burnout. ${ }^{5}$ In studies of resilience-building programs in nursing, social work, clinical psychology, and medical residency programs, common factors were evident across programs. ${ }^{6-9}$ Model programs included structures to increase positive mentoring; promote physical, emotional, and spiritual self-care; encourage behavioral and cognitive coping strategies; allow for self-reflection; foster social connections; and promote a sense of control. ${ }^{9}$

Similar to trainees in other healthcare professions, graduate students in Communication Sciences and Disorders (CSD) experience high demands on their personal resources before and during graduate training. Competition for graduate programs is high. Students accepted in graduate programs typically enter with a track record of successfully managing time and personal demands. However, research suggests the population of students entering CSD graduate programs, primarily women and high achieving students, are at an increased risk for anxiety and depression compared with male students and average achieving college students. ${ }^{10,11}$ Upon entering graduate level training, additional academic and clinical expectations tax students' time, health, and relationships. The predisposition of high achieving students and the new demands of graduate school place CSD graduate students at risk for future professional burnout or mental health challenges.

Although research specifically related to development of resilience in healthcare professionals is emerging, research examining personal resilience has been conducted for years. Current models of resilience suggest that multiple factors contribute to an individual's resilience in the face of difficult circumstances. Factors that have been associated with resilience include biological contributions such as childhood attachment, strength of an individual's beliefs and practices, positive environmental factors such as social support, and productive individual coping strategies. ${ }^{12}$

In a research review of resilience in practicing healthcare professionals, Jackson, Firtko, and Edenborough identified five core factors associated with individuals who thrived in spite of adversity. ${ }^{13}$ These individuals sustained positive professional networks and mentoring, maintained positivity through optimism and laughter, developed insight into their own risks and strengths, developed life balance and spirituality, and purposefully reflected on difficult circumstances to create meaning from the challenges. ${ }^{13}$

The purpose of this current project was to examine two dimensions related to future resilience in CSD graduate students. First, we examined lifestyle and personal factors contributing to stress and wellness in CSD graduate students and compared those trends to patterns identified in a regional survey of college students. Second, we adopted the framework of Jackson and colleagues and examined patterns of strengths and vulnerabilities in the same CSD graduate students in five areas known to be associated with resilience in healthcare professionals..$^{13}$ The areas of interest we examined were: positive professional networks and mentoring opportunities; maintaining positivity; student insight into their own risks and strengths; student perceptions of life balance; and indicators that students were making meaning in challenging circumstances.

Regarding student life stresses, we hypothesized that CSD graduate students might have fewer life stresses than a general population of college-age students, given their history of successfully managing multiple demands to achieve academic success. Regarding resilience indicators, we hypothesized that given the students' newness to the field, they would have weaker indicators of resilience in sustaining positive professional networks and mentoring as well as less developed personal insight into their own risks and strengths. Research evidence suggests high achieving students have a higher incidence of anxiety and depression than their moderately achieving peers, which led us to believe maintaining positivity might be an area of weakness for CSD graduate students. ${ }^{10}$ From previous literature, we hypothesized that students drawn to a helping profession in CSD would show strength in the two final indicators of resilience - perception of life balance and making meaning in challenging circumstances. ${ }^{14}$ 


\section{METHOD}

\section{Participants}

One hundred and forty-six, first and second year CSD master's degree students from Midwestern programs completed an online survey regarding stress and resilience. Ninety-five percent of participants were women; five percent were men. The majority of students were pursuing a master's degree in speech-language pathology. See Table 1 for demographic information.

Table 1. Demographics

\begin{tabular}{|c|c|}
\hline Characteristics & Percent \\
\hline \multicolumn{2}{|l|}{ Year in program } \\
\hline 1 st year & $47.3 \%$ \\
\hline $2^{\text {nd }}$ year & $48.6 \%$ \\
\hline Other & $4.1 \%$ \\
\hline \multicolumn{2}{|l|}{ Number of students in cohort } \\
\hline$<15$ & $13 \%$ \\
\hline $16-20$ & $50.7 \%$ \\
\hline $21-25$ & $10.3 \%$ \\
\hline$>25$ & $26 \%$ \\
\hline \multicolumn{2}{|l|}{ Age in years } \\
\hline $20-23$ & $56 \%$ \\
\hline $24-29$ & $40 \%$ \\
\hline $30-39$ & $3 \%$ \\
\hline $40+$ & $1 \%$ \\
\hline \multicolumn{2}{|l|}{ Relationship status } \\
\hline Single & $22.1 \%$ \\
\hline Committed Relationship & $59.3 \%$ \\
\hline Married & $13.1 \%$ \\
\hline Other & $5.5 \%$ \\
\hline \multicolumn{2}{|l|}{ Number of children } \\
\hline None & $96.5 \%$ \\
\hline 1 child & $1.4 \%$ \\
\hline 2 children & $1.4 \%$ \\
\hline $3+$ children & $.7 \%$ \\
\hline \multicolumn{2}{|l|}{ Gender } \\
\hline Man & $4.1 \%$ \\
\hline Woman & $94.5 \%$ \\
\hline Transgender & $0 \%$ \\
\hline Prefer not to disclose & $1.4 \%$ \\
\hline
\end{tabular}

\section{Materials}

A 20-question electronic survey was designed using Qualtrics online survey platform (https://www.qualtrics.com/). Five rating questions for the first section were replicated from a broad college student health review in the Minnesota State University System..$^{19}$ The first of the survey questions included a list of 20 items the individual rated as either absent; present, but not affecting academics; or present and affecting academics. The remaining 13 multiple choice and Likert style questions were created by the first author and research assistants related to the five focus areas of resilience. ${ }^{13}$ All questions in the second section of the survey were formulated based on previous literature and students' personal experiences. Two open-ended questions were included in the survey; the results of these questions are not reviewed in this paper. At the end of the survey, participants responded to 6 demographic questions.

A rough draft of the survey was piloted with five local participants and specific question wording was adjusted based on feedback from those pilot participants. All questions were presented in the same order for all participants. All survey questions and research procedures met St Cloud State University Institutional Review Board criteria for human subjects' research. 


\section{Procedure}

Members of the research team contacted the department chairs of five Midwestern master's degree programs in CSD via email and asked them to forward an explanation of the survey and electronic survey link to all master's degree students in their program. In the email to students, the project was described as a survey gathering information about graduate student wellness habits and beliefs. The survey was open for two weeks. One week before the survey closed, department chairs were sent a reminder email and asked to forward the reminder to all students. As an incentive to participate, individuals who completed the survey were offered the chance to enroll in a drawing for a $\$ 25$ Amazon gift card.

\section{RESULTS}

Of 304 possible participants, 146 students completed the survey, resulting in a $48 \%$ return rate. Results are presented below.

\section{Survey Part One: Personal \& Life Stresses}

In the first section of the survey, students examined a list of 20 personal life stresses and identified stresses that were either (1) not present in their life, (2) present but not affecting academics, or (3) present and affecting academics. Below we outline life stresses present in $20 \%$ or greater of the CSD students and then compare areas where CSD students and the general population showed significant differences in life stress patterns. See Table 2 for a side-by-side comparison of top life stresses.

\section{Top life stresses}

Regarding personal life stresses, more than $20 \%$ of CSD students rated the following areas as present in their lives, but not affecting academics: general stress, concerns for a family member or friend with personal struggles, financial difficulties, excessive non-academic computer or internet use, upper respiratory infections, sleep difficulties, mental health conditions, and alcohol use. The top life stresses in CSD students were similar to the top life stresses identified in the general college student population.

In contrast, when asked which life stresses were present and affecting their academics, a smaller percentage of CSD students reported life stresses directly impacting their academic performance compared with reports from a general college student population. Despite this generally positive trend in CSD students' management of life stresses, $20 \%$ or more of CSD students reported life stresses as both present and affecting academics in three areas: general stress (50\%), sleep difficulties $(27.70 \%)$, and mental health conditions (20.10\%). These numbers represent additional students beyond those reporting the presence of the stress, without a direct impact on academics. For example, $43.33 \%$ of CSD students reported general stress without academic impact, $50.00 \%$ of CSD students reported general stress which impacted their academics. Therefore, a total of $93.33 \%$ of CSD students reported the presence of general stress.

Chi-Square analysis using the Kruskal-Wallis test indicated a significant difference in the percentage of CSD students reporting the presence of general stress, sleep difficulties, presence of mental health condition, concern for a friend or family member, presence of a chronic health condition, and food insecurity (regardless of whether or academics were affected) as compared with the general college student group. CSD graduate students more frequently reported high general stress, presence of a mental health condition, concern for a friend or family member, and presence of a chronic health condition compared with the general college student group. CSD graduate students less frequently reported sleep difficulties and food insecurity as compared with the general college student group.

\section{Managing stress}

When asked to rate their ability to manage stress effectively, the majority of CSD students $(59.40 \%)$ rated themselves a 7 or 8 on a 10 - point scale ( $1=$ ineffective at managing stress; $10=$ very effective at managing stress). This is compared to $39 \%$ of general students who rated themselves a 7 or 8 on the same question $\left(\chi^{2}=9.05, p=.003\right)$. These results suggest that CSD students perceive themselves as more effective in stress management than do their general college student peers.

\section{Sleep patterns}

When asked how many days in the past week they awoke feeling rested, $56 \%$ of CSD students reported they awoke feeling rested between 0-3 days. Trends from the general college student survey were similar. Forty-nine percent of college students reported they awoke feeling rested between 0-3 days. Of note, Kruskal-Wallis tests were significant for differences in reported percentage of students who reported feeling rested 6-7 days of the past week $\left(\chi^{2}=77.04, p=<.001\right)$. A minority of CSD students $(10.70 \%)$ reported feeling rested 6-7 days of the past week. Seventeen percent of general college students reported feeling rested 6-7 days of the past week. Though sleep trends were similar in direction, these results suggest many CSD graduate students were not feeling sufficiently rested most days of the week; this pattern was noted to a greater degree in CSD graduate students than in the general college student population. Although in a previous question, CSD students were less likely to indicate they had "sleep difficulties" compared with college peers, their reported number of days achieving sufficient rest suggests otherwise. 
Table 2. Personal and Life Stresses: Effect on Academics for CSD Graduate Students and General College Population Question: During the past 12 months, how have the following affected your academic performance? (Please select the most appropriate response option)

\begin{tabular}{|c|c|c|c|c|c|c|c|c|c|c|c|c|c|}
\hline & \multicolumn{4}{|c|}{ I do not have this issue } & \multicolumn{4}{|c|}{$\begin{array}{l}\text { I have this issue; } \\
\text { my academics are not } \\
\text { affected }\end{array}$} & \multicolumn{4}{|c|}{$\begin{array}{l}\text { I have this issue; } \\
\text { my academics are } \\
\text { affected }\end{array}$} & \multirow{3}{*}{$\begin{array}{c}\text { Kruskal- } \\
\text { Wallis } \\
\text { Test }\end{array}$} \\
\hline & \multicolumn{2}{|c|}{$\begin{array}{c}\text { CSD } \\
(\mathrm{N}=146)\end{array}$} & \multicolumn{2}{|c|}{$\begin{array}{l}\text { General } \\
\text { College } \\
(\mathrm{N}=596)\end{array}$} & \multicolumn{2}{|c|}{$\begin{array}{c}\text { CSD } \\
(\mathrm{N}=146)\end{array}$} & \multicolumn{2}{|c|}{$\begin{array}{c}\text { General } \\
\text { College } \\
(\mathrm{N}=596)\end{array}$} & \multicolumn{2}{|c|}{$\begin{array}{c}\text { CSD } \\
(\mathrm{N}=146)\end{array}$} & \multicolumn{2}{|c|}{$\begin{array}{c}\text { General } \\
\text { College } \\
(\mathrm{N}=596)\end{array}$} & \\
\hline & $\%$ & $\mathrm{n}$ & $\%$ & $\mathrm{n}$ & $\%$ & $\mathrm{n}$ & $\%$ & $n$ & $\%$ & $\mathrm{n}$ & $\%$ & $n$ & \\
\hline Stress & 6.50 & 10 & 27.00 & 167 & 43.33 & 65 & 39.00 & 244 & 50.00 & 75 & 29.00 & 182 & $p<.001$ \\
\hline Sleep difficulties & 47.70 & 74 & 53.20 & 329 & 22.30 & 33 & 39.00 & 244 & 27.70 & 41 & 29.00 & 182 & $p<.001$ \\
\hline $\begin{array}{l}\text { Any mental health } \\
\text { issues }\end{array}$ & 53.50 & 83 & 68.80 & 426 & 24.00 & 36 & 13.00 & 78 & 20.67 & 31 & 15.00 & 94 & $p<.001$ \\
\hline $\begin{array}{l}\text { Excessive } \\
\text { computer/internet } \\
\text { use (nonacademic) }\end{array}$ & 60.00 & 93 & 57.00 & 353 & 24.00 & 36 & 25.00 & 157 & 14.00 & 21 & 14.00 & 84 & $p=.623$ \\
\hline $\begin{array}{l}\text { Concern for a } \\
\text { friend/family } \\
\text { member }\end{array}$ & 49.00 & 76 & 66.20 & 410 & 36.00 & 54 & 21.00 & 127 & 13.33 & 20 & 9.00 & 58 & $p<.001$ \\
\hline $\begin{array}{l}\text { Upper respiratory } \\
\text { infection }\end{array}$ & 60.60 & 94 & 67.20 & 416 & 25.33 & 38 & 18.00 & 111 & 12.00 & 18 & 11.00 & 67 & $p=.118$ \\
\hline Financial difficulties & 45.20 & 70 & 55.30 & 342 & 42.67 & 64 & 28.00 & 170 & 10.67 & 16 & 13.00 & 82 & $p=.087$ \\
\hline $\begin{array}{l}\text { Relationship issues } \\
\text { (Not a roommate or } \\
\text { housemate) }\end{array}$ & 74.80 & 116 & 75.10 & 465 & 16.00 & 24 & 12.00 & 71 & 6.67 & 10 & 9.00 & 58 & $p=.961$ \\
\hline Any Disability & 88.40 & 137 & 86.40 & 535 & 3.33 & 5 & 5.00 & 28 & 5.33 & 8 & 5.00 & 32 & $p=.621$ \\
\hline $\begin{array}{l}\text { Relationship issues } \\
\text { (roommate or } \\
\text { housemate) }\end{array}$ & 76.10 & 118 & 79.20 & 490 & 18.00 & 27 & 13.00 & 79 & 3.33 & 5 & 4.00 & 26 & $p=.347$ \\
\hline $\begin{array}{l}\text { Eating } \\
\text { disorder/problems }\end{array}$ & 89.00 & 138 & 91.10 & 564 & 4.67 & 7 & 3.00 & 19 & 3.33 & 5 & 2.00 & 13 & $p=.221$ \\
\hline Chronic conditions & 80.00 & 124 & 85.80 & 531 & 14.67 & 22 & 9.00 & 55 & 2.67 & 4 & 1.00 & 8 & $p=.023$ \\
\hline Alcohol Use & 72.90 & 113 & 74.60 & 462 & 23.33 & 35 & 18.00 & 114 & 1.33 & 2 & 3.00 & 20 & $p=.668$ \\
\hline $\begin{array}{l}\text { Sexually transmitted } \\
\text { infection }\end{array}$ & 94.80 & 147 & 94.70 & 586 & 1.33 & 2 & 1.00 & 7 & 0.67 & 1 & 0.20 & 1 & $p=.551$ \\
\hline Sexual assault & 94.80 & 147 & 93.70 & 580 & 1.33 & 2 & 1.00 & 8 & 0.67 & 1 & 0.80 & 5 & $p=.884$ \\
\hline Food insecurity & 92.90 & 144 & 86.10 & 533 & 3.33 & 5 & 7.00 & 45 & 0.67 & 1 & 2.00 & 15 & $p=.018$ \\
\hline Serious Injury & 94.80 & 147 & 92.40 & 572 & 2.00 & 3 & 2.00 & 15 & 0.00 & 0 & 2.00 & 9 & $p=.240$ \\
\hline $\begin{array}{l}\text { Pregnancy (yours or } \\
\text { your partner's) }\end{array}$ & 95.50 & 148 & 93.70 & 580 & 1.33 & 2 & 1.00 & 6 & 0.00 & 0 & 1.00 & 6 & $p=.570$ \\
\hline Marijuana use & 92.90 & 144 & 89.20 & 552 & 3.36 & 5 & 7.00 & 40 & 0.00 & 0 & 0.50 & 3 & $p=.084$ \\
\hline Being Homeless & 96.80 & 150 & 94.00 & 582 & 0.00 & 0 & 1.00 & 6 & 0.00 & 0 & 0.80 & 5 & $p=.093$ \\
\hline
\end{tabular}

\section{Lifestyle health patterns}

In addition to general life stressors, CSD students were asked about changes in their lifestyle (i.e. exercise, weight, eating) since the start of graduate school. Many CSD students (68\%) reported exercising less currently as compared to their patterns before graduate school. Further, $49 \%$ of CSD students judged their current weight to have changed for the worse since beginning graduate school. In addition, $49 \%$ of CSD graduate students selected the statement "I eat less nutritious food" since starting graduate school. We did not have parallel data to compare these trends with general college student patterns. 


\section{Survey Part Two: Patterns in Five Factors Related to Resilience}

In the second part of the survey, CSD graduate students responded to statements in five areas related to resilience. Questions were asked using a 4-point Likert scale ranging ( $4=$ definitely; $3=$ somewhat; $2=$ very little; $1=$ not at all). Major results in the five areas are summarized in the text. See Table 3 for a complete summary of the survey data.

\section{Positive professional networks and mentoring}

When asked about professional networks and mentoring, 70\% of CSD students reported having a close connection with at least one faculty member and a majority reported both close friendships (61\%) and a positive professional network (74\%) within their student cohort. Fifty percent of CSD students indicated that classmates served as mentors for class or clinic.

\section{Maintaining positivity}

When asked about maintaining positivity, most CSD students reported a high level of confidence in faculty expertise (84\%) and leadership (66\%). Seventy-nine percent of students felt confident in their abilities to complete the requirements of their program. When asked about energy and attitudes for daily tasks, positivity was lower. Forty-one percent of students felt optimism and interest in doing school or clinic related tasks nearly every day. A smaller percentage of students $(26 \%)$ felt energetic and hopeful about graduate school nearly every day. Notably, a substantial number of CSD students $(20.70 \%)$ felt energetic or hopeful about graduate school only a few days a week or not at all.

\section{Developing insight into own risks and strengths}

For this topic, CSD students were asked about effective methods for managing their stress as well as the opportunities present for personal reflection. Students identified the following four methods as most effective for managing stress: relationship maintenance, exercise, watching television or listening to music, and getting out in nature. To their credit, students also reported these strategies as the top four methods they used to manage stress. Students showed self-insight and follow-through with regard to stress management.

When asked about opportunities to reflect on their strengths and weaknesses, $59 \%$ of students reported they definitely had opportunities to reflect during graduate school. Seventy percent felt confident in their personal knowledge of their strengths and weaknesses. A similarly high percentage (62\%) indicated they definitely used knowledge of personal strengths and weaknesses to shape their personal learning goals and strategies.

\section{Life balance}

When asked about life balance, $17 \%$ of students definitely agreed with the statement, "even though graduate school keeps me busy, my life feels balanced." A similar percentage, $18 \%$, agreed that, "unexpected changes to my workload are manageable." Fifty-one percent of students strongly perceived faculty as supportive and accommodating of life circumstances, but fewer students $(30 \%)$ stated they definitely felt comfortable asking for accommodations if needed. In fact, $25 \%$ of students surveyed indicated they were hesitant to ask for accommodations.

\section{Making meaning of challenging circumstances}

Overwhelmingly $(90 \%)$, students definitely agreed with the statement, "my work has potential to bring value to the larger community." Further, $77 \%$ of students viewed challenges in graduate school as contributing to personal and professional growth.

Table 3. Patterns of CSD Student Resilience in Five Areas

\begin{tabular}{|c|c|c|c|c|c|c|c|c|c|}
\hline \multirow{2}{*}{$\begin{array}{l}\text { Area } \\
\text { Positive }\end{array}$} & Question & \multicolumn{2}{|c|}{$\begin{array}{c}\text { Definitely } \\
4 \\
\end{array}$} & \multicolumn{2}{|c|}{$\begin{array}{c}\text { Somewhat } \\
3\end{array}$} & \multicolumn{2}{|c|}{$\begin{array}{l}\text { A Little } \\
2\end{array}$} & \multicolumn{2}{|c|}{$\begin{array}{c}\text { Not at All } \\
1\end{array}$} \\
\hline & e Professional Networks and Mentoring & $\%$ & $\mathbf{n}$ & $\%$ & $\mathbf{n}$ & $\%$ & $\mathbf{n}$ & $\%$ & $\mathrm{n}$ \\
\hline & $\begin{array}{ll}1 & \text { I have a positive professional network } \\
\text { with my classmates. }\end{array}$ & 74.00 & 109 & 23.00 & 34 & 1.00 & 2 & 1.00 & 2 \\
\hline & $\begin{array}{l}\text { I receive direct mentoring from } \\
\text { classmates/colleagues for class } \\
\text { and/or clinic. }\end{array}$ & 50.00 & 74 & 33.00 & 49 & 14.00 & 21 & 2.00 & 3 \\
\hline & $\begin{array}{ll}3 & \text { I have a close connection with at } \\
\text { least one faculty member. }\end{array}$ & 70.00 & 98 & $\mathrm{~N} / \mathrm{A}$ & $\mathrm{N} / \mathrm{A}$ & $\mathrm{N} / \mathrm{A}$ & $\mathrm{N} / \mathrm{A}$ & 3.00 & 43 \\
\hline & $\begin{array}{l}4 \text { I have close friendships within my } \\
\text { cohort/program. }\end{array}$ & 61.00 & 89 & 31.00 & 45 & 7.00 & 10 & 2.00 & 3 \\
\hline
\end{tabular}




\begin{tabular}{|c|c|c|c|c|c|c|c|c|c|}
\hline & & $\%$ & $\mathbf{n}$ & $\%$ & $\mathbf{n}$ & $\%$ & $\mathbf{n}$ & $\%$ & $\mathbf{n}$ \\
\hline \multicolumn{10}{|c|}{ Maintaining Positivity } \\
\hline 5 & $\begin{array}{l}\text { Overall, I have confidence in faculty } \\
\text { expertise. }\end{array}$ & 84.00 & 123 & 13.00 & 19 & 3.00 & 5 & $\mathrm{~N} / \mathrm{A}$ & $\mathrm{N} / \mathrm{A}$ \\
\hline 6 & $\begin{array}{l}\text { I have confidence in faculty } \\
\text { leadership. }\end{array}$ & 66.00 & 97 & 30.00 & 44 & 2.00 & 3 & 2.00 & 3 \\
\hline 7 & $\begin{array}{l}\text { I am confident I can successfully } \\
\text { complete the requirements of my } \\
\text { program }\end{array}$ & 79.00 & 115 & 19.00 & 27 & 1.00 & 1 & 2.00 & 3 \\
\hline 8 & $\begin{array}{l}\text { I feel optimism and interest in doing } \\
\text { school or clinic related things }{ }^{*}\end{array}$ & 41.00 & 62 & 45.00 & 67 & 11.00 & 17 & 0.00 & $\mathrm{~N} / \mathrm{A}$ \\
\hline 9 & $\begin{array}{l}\text { I feel energetic and hopeful about } \\
\text { graduate school }{ }^{*}\end{array}$ & 26.00 & 39 & 51.00 & 76 & 18.00 & 27 & 2.70 & 4 \\
\hline \multicolumn{10}{|c|}{ Developing Insight into Own Risks and Strengths } \\
\hline 10 & $\begin{array}{l}\text { I have the opportunity to reflect on my } \\
\text { strengths and weaknesses. }\end{array}$ & 59.00 & 86 & 38.00 & 56 & 3.00 & 4 & $\mathrm{~N} / \mathrm{A}$ & $N / A$ \\
\hline 11 & $\begin{array}{l}\text { I understand how my } \\
\text { strengths/weaknesses affect my } \\
\text { professional skills. }\end{array}$ & 71.00 & 103 & 27.00 & 39 & 3.00 & 4 & $\mathrm{~N} / \mathrm{A}$ & $\mathrm{N} / \mathrm{A}$ \\
\hline 12 & $\begin{array}{l}\text { I use knowledge of my strengths and } \\
\text { weaknesses to shape personal } \\
\text { learning goals and strategies. }\end{array}$ & 62.00 & 91 & 36.00 & 53 & 2.00 & 3 & $\mathrm{~N} / \mathrm{A}$ & $\mathrm{N} / \mathrm{A}$ \\
\hline \multicolumn{10}{|c|}{ Life Balance } \\
\hline 13 & $\begin{array}{l}\text { Even though graduate school keeps } \\
\text { me busy, my life feels balanced. }\end{array}$ & 16.00 & 26 & 59.00 & 86 & 19.00 & 27 & 6.00 & 9 \\
\hline 14 & $\begin{array}{l}\text { Unexpected changes to my workload } \\
\text { are manageable. }\end{array}$ & 18.00 & 26 & 69.00 & 101 & 10.00 & 15 & 3.00 & 4 \\
\hline 15 & $\begin{array}{l}\text { I feel comfortable requesting } \\
\text { accommodations if life circumstances } \\
\text { arise (e.g. child care, commuting, } \\
\text { personal health, family situations) }\end{array}$ & 30.00 & 44 & 36.00 & 53 & 20.00 & 29 & 5.00 & 7 \\
\hline 16 & $\begin{array}{l}\text { My department and colleagues have } \\
\text { been supportive and accommodating } \\
\text { when outside life circumstances arise } \\
\text { (e.g. child care, commuting, personal } \\
\text { health, family situations). }\end{array}$ & 51.00 & 75 & 21.00 & 31 & 3.00 & 4 & 1.00 & 2 \\
\hline \multicolumn{10}{|c|}{ Making Meaning of Challenging Circumstances } \\
\hline 17 & $\begin{array}{l}\text { Challenges I face as a graduate } \\
\text { student can contribute positively to } \\
\text { my personal and professional growth. }\end{array}$ & 77.00 & 112 & 23.00 & 33 & 1.00 & 1 & $\mathrm{~N} / \mathrm{A}$ & $\mathrm{N} / \mathrm{A}$ \\
\hline 18 & $\begin{array}{l}\text { My work as an SLP has potential to } \\
\text { bring value to the larger community. }\end{array}$ & 90.00 & 131 & 10.00 & 14 & 1.00 & 1 & $\mathrm{~N} / \mathrm{A}$ & $N / A$ \\
\hline
\end{tabular}

\section{DISCUSSION}

Within graduate school programs, CSD students face multiple demands, potentially taxing their personal resources and increasing their risk for burnout. In our research, we examined two major questions: 1) what life and personal factors contribute to stress and wellness in CSD graduate students and how do these trends compare with patterns in general college student populations? 2) What patterns of strength and vulnerability do CSD graduate students display in areas known to be related to resilience in healthcare professionals?

\section{Life and Personal Stresses}

In response to the first research question, our survey results indicated that CSD graduate students were affected with similar life stresses as college students in general. For the most part, CSD students appeared to manage life stresses with limited direct impact on their academic performance. This pattern of academic success in spite of life stresses is not unexpected, given that 
students in most CSD programs have maintained a sufficiently strong academic profile to be accepted into graduate school. Of note, is that CSD students were not immune to the stresses other college students face, but indeed shared many of the same life stresses such as financial struggles, worries about friends or family members with struggles, excessive computer/internet use, health and mental health issues, inadequate sleep, and alcohol use. These underlying factors in CSD students may not be obvious to outside observers because of their limited academic impact for most students.

Another important pattern observed was that CSD students displayed a significantly greater presence of chronic health and mental health conditions than general college student peers as well as a higher reported level of stress. Also, a greater percentage of CSD students reported emotional concerns about well-being of friends and family members compared to college age peers. As individuals drawn to healthcare professions, CSD students may play a supportive role for struggling members of their individual communities. A sizeable number of CSD students acknowledged that some of these life stresses were affecting their academics.

For more than one in five CSD graduate students, sleep difficulties, generalized stress, and mental health issues were reported to be directly impacting academics. These trends, in combination with the additional students who cited similar struggles without academic impact, suggest that nearly $50 \%$ of CSD graduate students struggled to maintain adequate sleep and effectively manage mental health. Students may not have perceived these stresses as directly affecting their academic performance, but many students acknowledged the presence of multiple, stress-related life factors. These trends are important as CSD faculty determine how to best support CSD students' personal and professional resilience.

In line with the diathesis-stress model, as external demands for CSD students increase, underlying personal factors could have increased impact on students' academic, clinical, and future professional success. ${ }^{21}$ Indeed, our data on lifestyle patterns suggest that CSD graduate students often experienced negative changes in health patterns (exercise, weight changes, eating) during graduate school.

\section{Indicators of Resilience - Strengths}

In the second part of our research, we examined CSD graduate students' strengths and vulnerabilities related to personal and professional resilience. CSD students as a group exhibited many strengths that will support their present and future resilience. Most students reported having positive relationships and mentoring from faculty and classmates within their graduate programs. They described positive attitudes about school and the value of their work in CSD. Students conveyed self-knowledge of their personal strengths and weaknesses and indicated they had frequent opportunities for self-reflection throughout their programs.

With regard to managing stress, students showed insight into methods that most effectively reduced their stress and typically used these stress management methods they had cited as effective (e.g. relationship maintenance, exercise, relaxing to TV or music, and getting out in nature). This pattern suggests that most students showed strength in selecting and implementing effective stress management practices. These survey findings as a whole indicate that CSD graduate students exhibit many foundational strengths that will support future personal and professional resilience.

\section{Indicators of Resilience - Vulnerabilities}

Despite the above positive predictors of future resilience, some vulnerabilities were identified in CSD students from our survey results. As mentioned previously, more than half of CSD graduate students reported experiencing multiple life stresses. Some of the stress management methods reported by students to be most effective (e.g. exercise and getting enough sleep) may not be consistently used because of time limitations during graduate school. Consistent with this interpretation, most CSD students reported negative changes in nutrition and exercise habits since beginning graduate school as well as very few days of feeling fully rested.

Potential vulnerabilities to resilience were also evident related to students' capacity to maintain positivity and life balance. Although the majority of CSD students felt positive about their career choice and confident in faculty expertise, a much smaller portion of students maintained this same level of optimism in daily tasks. Not surprisingly, students also indicated challenges in maintaining life balance during graduate school. Few students reported a high level of confidence in their ability to maintain adequate life balance and handle unexpected changes in workload during graduate school. Importantly, students reported a strong belief that faculty and supervisors cared about their personal lives, but only one third of students strongly stated they would feel comfortable asking for accommodations for life events.

\section{Implications}

What implications are present for CSD programs seeking to promote resilience in future professionals? Research suggests that professional programs can support the development of personal and professional resilience in students training for healthcare 
professions. A starting point is for both students and faculty to identify traits related to personal and professional resilience and then determine how to promote these traits. For some programs, an initial focus may be on both faculty and students identifying traits related to resilience. A second priority is for faculty and students to understand which of these traits are strengths already present in their student and faculty populations and which are areas to develop. This survey project provides a starting point to describe patterns in CSD master's programs within the Midwestern region of the US. Optimistically, students appear to sense that faculty and their peers care about them. Some student needs may be addressed through relatively small changes such as wellness check-ins, adjustment of timelines, and empowering reasonable requests for personal accommodations.

\section{Limitations and Future Directions}

As with any research, this project has its limitations. The sample size of 146 participants was adequate, but certainly a small representation of the overall CSD student population in the US. The students surveyed were all in Midwestern CSD programs. It is possible that some life factors may be influenced by regional circumstances. The sample was primarily women, which may be a limitation, but is also consistent with the student and professional population of interest. We did not have baseline information to compare an individual student's current state of wellness with patterns before graduate school. Student report as a means for gathering information presents some limits in objectivity, but was reasonable for the focus of this project.

\section{CONCLUSIONS}

Despite limitations, the present study provides insight into factors potentially impacting the wellness and resilience of CSD graduate students. The data from this survey may provide direction for CSD programs seeking to intentionally promote resilience for students completing graduate programs. Knowing that burnout is an ongoing risk for healthcare professionals in general and CSD professionals specifically, faculty in graduate programs need to understand factors contributing to resilience. With a deeper understanding of these factors, faculty in graduate training programs can proactively consider ways to address both individual and contextual methods for fostering resilience.

\section{REFERENCES}

1. Felton JS. Burnout as a clinical entity-its importance in health care workers. Occupational Medicine. 1998; 48(4), 237-250.

2. Poulin J, Walter C. Social worker burnout: A longitudinal study. In Social Work Research and Abstracts. 1993; 29 (4) 5Oxford University Press.

3. Wisniewski L, Gargiulo RM. Occupational stress and burnout among special educators: A review of the literature. Journal of Special Education. 1997; 31(3), 325.

4. Denz-Penhey H, \& Murdoch C. Personal resiliency: Serious diagnosis and prognosis with unexpected quality outcomes. Qualitative Health Research. 2008; 18, 391-404.

5. McCann, C. M., Beddoe, E., McCormick, K., Huggard, P., Kedge, S., Adamson, C., Huggard, J.. Resilience in the health professions: A review of recent literature. International Journal of Wellbeing, 2013; 3 (1), 60-81.

6. Drolet BC, Rodgers S. A comprehensive medical student wellness program-design and implementation at Vanderbilt School of Medicine. Academic Medicine. 2010; 85(1), 103-110.

7. Eckleberry-Hunt J, Van Dyke A, Lick D, Tucciarone J. Changing the conversation from burnout to wellness: Physician wellbeing in residency training programs. Journal of Graduate Medical Education. 2009; 1 (2), 225-230.

8. Place S, Talen M. Creating a culture of wellness: Conversations, curriculum, concrete resources, and control. The International Journal of Psychiatry in Medicine. 2013; 45(4), 333-344.

9. McAlister M, McKinnon J. The importance of teaching and learning resilience in the health disciplines: A critical review of the literature. Nurse Education Today. 2009; 29, 371-379.

10. Eisenberg, D., Gollust, S.E., Golberstein, E., Hefner, J. (2007). Prevalence and correlates of depression, anxiety, and suicidality among university students. American Journal of Orthopsychiatry, 2007; 77(4), 534-542.

11. Pham, S. Addressing common mental health issues prevalent among honors college student. (2017). Honors Theses. 2891. http://scholarworks.wmich.edu/honors theses/2891

12. Ledesma, J. Conceptual frameworks and research: Models of resilience in leadership. Sage Open. July-September 2014; 18. DOI: 10.1177/2158244014545464. www.sgo.sagepub.com.

13. Jackson D, Firtko A, Edenborough M. Personal resilience as a strategy for surviving and thriving in the face of workplace adversity: a literature review. Journal of Advanced Nursing. 2007; 60(1), 1-9

14. Baggs TW. Has speech-language pathology changed? Personality types of contemporary students. The Internet Journal of Allied Health Sciences and Practice. 2013 Jan 01;11(1), Article 5. 
15. Bamonti PM, Keelan CM, Larson N, Mentrikoski JM, Randall C L, Sly SK, ... McNeil DW. Promoting ethical behavior by cultivating a culture of self-care during graduate training: A call to action. Training and Education in Professional Psychology. 2014; 8(4), 253.

16. Fimian MJ, Lieberman RJ, Fastenau PS. Development and validation of an instrument to measure occupational stress in speech-language pathologists. Journal of Speech Language Hearing Research. 1991; 34(2), 439-446.

17. Marsh DT. Marilyn...and other offspring. Journal of the California Alliance for the Mentally III. 1996; 7, 4-6.

18. Maslach C, Leiter MP. Reversing burnout. Stanford Social Innovation Review. Stanford Graduate School of Business. 2005; 43-49. www.ssireview.com.

19. Health and health related behaviors: St Cloud State University Students. University of Minnesota College Student Health Survey. 2015; Boynton Health Service.

20. Hamaideh SH, Hamdan-Mansour, AM. Psychological, cognitive, and personal variables that predict college academic achievement among health sciences students. Nurse Education Today. 2014; 34 (5), 703-708.

21. Enns MW, Cox BJ, Clara, IP. Perfectionism and neuroticism: A longitudinal study of specific vulnerability and diathesisstress models. Cognitive therapy and Research. 2005. 29 (4), 463-478. 